\title{
Seroprevalence of Toxoplasmosis with ELISA and Rapid Diagnostic Test among Residents in Gyodong-do, Inchon city, Korea: A Four-Year Follow-up
}

\author{
Yeong Hoon Kim¹, Ji hoo Lee², Seong kyu Ahn³, Tong-Soo Kim³, Sung-Jong Hong ${ }^{4}$, Chom-Kyu Chong ${ }^{2}$, \\ Hye-Jin Ahn ${ }^{5}$, Ho-Woo Nam, \\ ${ }^{1}$ Department of Ophthalmology, College of Medicine, Catholic University of Korea, Seoul 06591, Korea; ' Genbody Inc., Cheonan 31116, Korea; \\ ${ }^{3}$ Department of Parasitology and Tropical Medicine and Inha Research Institute for Medical Sciences, Inha University School of Medicine, Incheon \\ 22333, Korea; ${ }^{4}$ Department of Medical Environmental Biology, Chung-Ang University College of Medicine, Seoul 06974, Korea; ${ }^{5}$ Department of \\ Parasitology, College of Medicine, Catholic University of Korea, Seoul 06591, Korea
}

\begin{abstract}
ELISA has been used for the diagnosis of toxoplasmosis, but it is being gradually replaced by a rapid diagnostic test (RDT). We compared and analyzed ELISA and RDT results using the sera collected during 4 consecutive years from residents of Gyodong-do (Island), Incheon-city, Korea. Sera from 921, 993, 940, and 838 adult residents were collected on a yearly basis (2010-2013). ELISA was performed by using a crude extract of $T$. gondii RH strain antigen and lgG/lgM RDT mounted with recombinant fragment of major surface antigen (SAG1), GST-linker-SAG1A, were applied to the sera. Comparison between groups was analyzed by the Student's t-test. The positive seroprevalence surged from $14.7 \%$ (135/921, 2010), 23.1\% (231/993, 2011), 23.6\% (222/940, 2012), and 32.1\% (269/838, 2013) by ELISA. In contrast, RDT showed a more moderate increasing trend from 21.7\% (200/921, 2010), 25.5\% (253/993, 2011), 28.9\% $(272 / 940,2012)$ and $33.1 \%(277 / 838,2013)$. Discrepancies between ELISA and RDT were noted near the cut-off value. At the OD 0.15-0.24 range, RDT could detect $16.1 \%$ (169/1051) more positives, which suggests an early or acute toxoplasmosis, but at the OD 0.25-0.34 range, ELISA could detect 35.9\% (92/256) more positives of possible chronic infections. Over the OD > 0.35 ELISA and RDT agreed in the majority of the cases. This surge in seroprevalence may be caused by the organic agriculture in addition to eating behavior or increase in pets among Koreans. These facts may be applied on a full-scale national survey using RDT to supplement ELISA to define the characteristics of the infection.
\end{abstract}

Key words: Toxoplasma gondii, seroprevalence, Gyodong-do (Island), RDT, ELISA

\section{INTRODUCTION}

Toxoplasma gondii, an apicomplexan zoonotic protozoan, is one of the most successful parasites widely prevalent in humans and animals worldwide. Felids are its definitive host, and all the other warm blooded animals, including humans, are its intermediate hosts. Toxoplasmosis is acquired by the infection with $T$. gondii through ingestion of tissue cysts from undercooked meat, or consuming food or water contaminated with oocysts. Another route of infection is from infected mother to her fetus via placental transmission of T. gondii, a process known as congenital toxoplasmosis [1-3]. Congenital

\footnotetext{
- Received 17 February 2017, revised 13 April 2017, accepted 23 April 2017.

*Corresponding author (howoo@catholic.ac.kr)

(C) 2017, Korean Society for Parasitology and Tropical Medicine

This is an Open Access article distributed under the terms of the Creative Commons

Attribution Non-Commercial License (http://creativecommons.org/licenses/by-nc/4.0)

which permits unrestricted non-commercial use, distribution, and reproduction in any

medium, provided the original work is properly cited.
}

toxoplasmosis may cause stillbirth or abortion in addition to serious damages to the fetus, such as severe neurological disorders after delivery [4,5]. Only a small percentage of exposed adult humans develop clinical symptoms following exposure, so that most cases show only mild symptoms or are asymptomatic. However, the infections can change into a chronic status, especially in the central nervous system of the individuals affected. These sometimes reactivate in immune compromised patients to cause toxoplasmic lymphadenitis, meningoencephalitis, or ocular toxoplasmosis [6-9].

Many serological tests have been developed to test anti-Toxoplasma antibodies in Korea. Of these, indirect latex agglutination (ILA) test had been used for several years because of its easiness to perform and its comparable sensitivity and specificity to the dye test after improvements by Tsubota et al. [10] and Kobayashi et al [11]. There have been many surveys on the seroprevalence of toxoplasmosis among various groups of patients in Korea, which resulted in the range from 1.9 to $5.8 \%$ 
with ILA test [12] and up to $7.7 \%$ with the more sensitive ELISA [13], all of which are still significantly lower by approximately $1 / 10$ than those of the other countries with a positive seroprevalence of 30 to $70 \%$ [3]. Recently, we have proved the maintained seroprevalence of toxoplasmosis in Jeju-do (Island) over 30 years $[12,14,15]$, which is higher than the other regions of Korea at $12.9 \%$ to $13.2 \%$. We also observed a very high seroprevalence rate of $17.0 \%$ in residents of Cheorwongun, located in mainland Korea, which suggests some changes in the toxoplasmic environment [16]. Although ELISA has been used widely in the diagnosis of toxoplasmosis, it is a time-consuming procedure, and there is a need for a skilled technician, which have resulted in its being replaced gradually by a rapid diagnostic test (RDT), the current universal trend for diagnosis.

Korea is on the verge of becoming an advanced country with an almost 100\% full health-coverage of its population, yet its seroprevalence of toxoplasmosis in certain areas is surging recently. The surge is worrying, and one factor contributing to it may be climatic changes as the Korean peninsula is experiencing sub-tropical weathers during the warm periods of the year.

The current study compared and analyzed ELISA and RDT for the detection of anti-Toxoplasma antibodies with the sera of residents in Gyodong-do (Island), Incheon, Korea for 4 years from 2010 to 2013. An explosive increase in the seroprevalence was noted in the area. The same results were observed both by ELISA and RDT, but discrepancies were present around the cutoff positive value of OD 0.25 in ELISA with RDT. We tried to postulate its significance and also the cause of the recent sudden surge of toxoplasmosis in this area.

\section{MATERIALS AND METHODS}

\section{Ethics statement}

This study was performed under the regulation of the IRB Committee of Chung-Ang University (no. 2010-06-03) and the IRB Committee of Inha University (no. 2012-28 and 2013008). This research adhered to the tenets of the Declaration of Helsinki. All participants were provided with a written informed consent, and no minors were involved in the study.

All procedures and handling of mice were conducted under an approved protocol by the Institutional Animal Care and Use Committee (IACUC) at the School of Medicine, Catholic University of Korea (no. CUMC-2015-0042-02, 2015-2017), which adhered to the regulations set under the Korean National Animal Protection Act. The RH strain of T. gondii has been provided by the National Veterinary Research and Quarantine Service, the Republic of Korea [17].

\section{Parasite and preparation of antigen}

The RH strain of T. gondii was maintained by peritoneal pas-

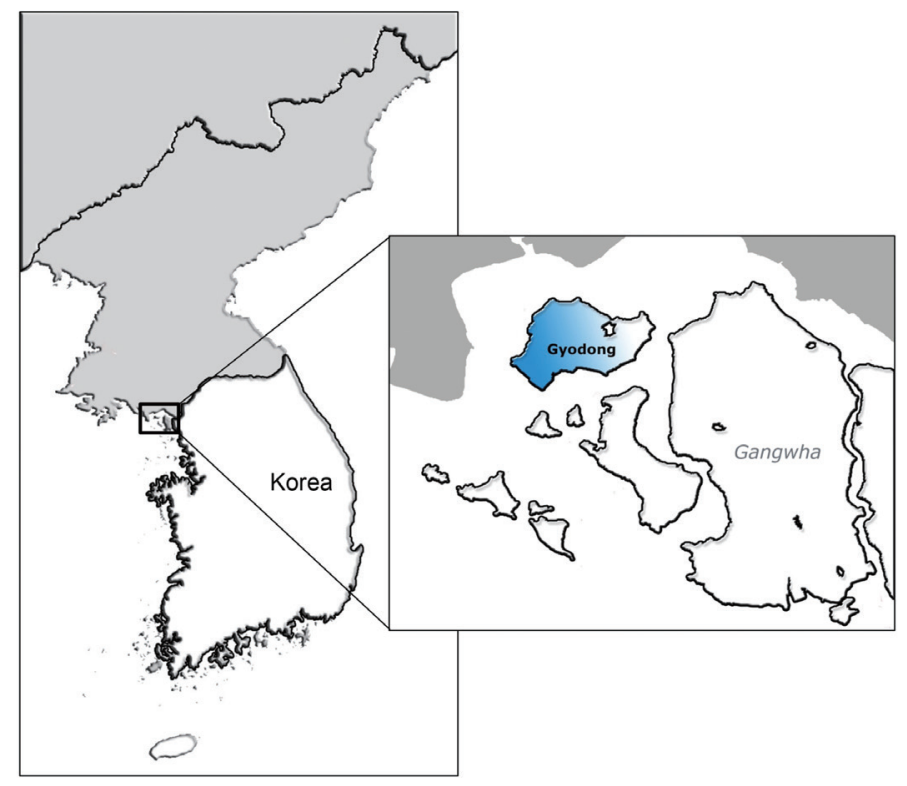

Fig. 1. The surveyed area. Gyodong-do (Island) administratively belongs to Gyodong-myeon, which is a part of Gangwha-gun, Incheon, in the western part of Korea. 
sages in BALB/c mice. The tachyzoites were purified by centrifugation over 40\% Percoll (Sigma-Aldrich Co., St. Louis, Missouri, USA) in PBS [18] and disrupted by sonification in a digital sonifier (Branson, Danbery, Connecticut, USA). The concentration of protein was measured with a Bio-Rad protein assay kit (Bio-Rad, Hercules, California, USA).

\section{Serum collection}

Sera of 921, 993, 940, and 838 adult residents in Gyodongdo (Gyodong-myeon, Gangwha-gun, Incheon, Korea) (Fig. 1) were collected on a yearly basis from 2010 to 2013 (Table 1). Both ELISA and RDT were performed on the samples to counter-check each other.

\section{ELISA}

The sera were checked for IgG antibody titers by ELISA using a crude extract RH strain antigen of $T$. gondii according to the method of Choi et al [13]. The optical density (OD) of duplicated samples were measured at $490 \mathrm{~nm}$ with a spectrophotometer (PerkinElmer Victor3, Turku, Finland) and compensated by comparing the OD of a standard positive serum in each plate. Comparison between groups was analyzed by the
Student's t-test.

\section{Rapid diagnostic test (RDT)}

IgG/IgM RDT mounted with recombinant fragment of major surface antigen (SAG1), GST-linker-SAG1A [14,19], were applied to the sera mentioned above. Briefly, $10 \mu \mathrm{l}$ of serum was applied to the RDT sample hole and eluted with RDT buffer a few seconds later. Reacting bands were read after 15-20 min and its density was determined arbitrarily as $0,+,++$ and +++ . A definite reactivity was determined as ++ (mid), while weaker and stronger reactivity compared to it was determined as + (weak) and +++ (strong). The final results were agreed upon by the 3 investigators.

\section{RESULTS}

\section{Seroprevalence}

The positive seroprevalence of the residents in Gyodong-do surged from $14.7 \%$ (135/921) in 2010 to $23.1 \%$ (231/993) in 2011 by ELISA. Subsequent years showed an increasing trend in the posivitive seroprevalence, to $23.6 \%$ (222/940) and 32.1\% (269/838) in 2012 and 2013, respectively (Table 1; Fig. 2).

Table 1. Seroprevalence of T. gondii by ELISA and RDT among residents in Gyodong-do (Island), Gangwha-gun, Incheon, Korea, 20102013

\begin{tabular}{lcccccc}
\hline Year & No. of sera & ELISA (\%) & RDT (\%) & ELISA only & ELISA/RDT & RDT only \\
\hline 2010 & 921 & $135(14.7)$ & $200(21.7)$ & 19 & $116(85.9)^{\star}$ & 84 \\
2011 & 993 & $231(23.1)$ & $253(25.5)$ & 28 & $203(87.9)$ & 50 \\
2012 & 940 & $222(23.6)$ & $272(28.9)$ & 24 & $198(89.2)$ & 74 \\
2013 & 838 & $269(32.1)$ & $277(33.1)$ & 39 & $230(85.5)$ & 47 \\
\hline
\end{tabular}

*\% of ELISA positive which are detected also by RDT.
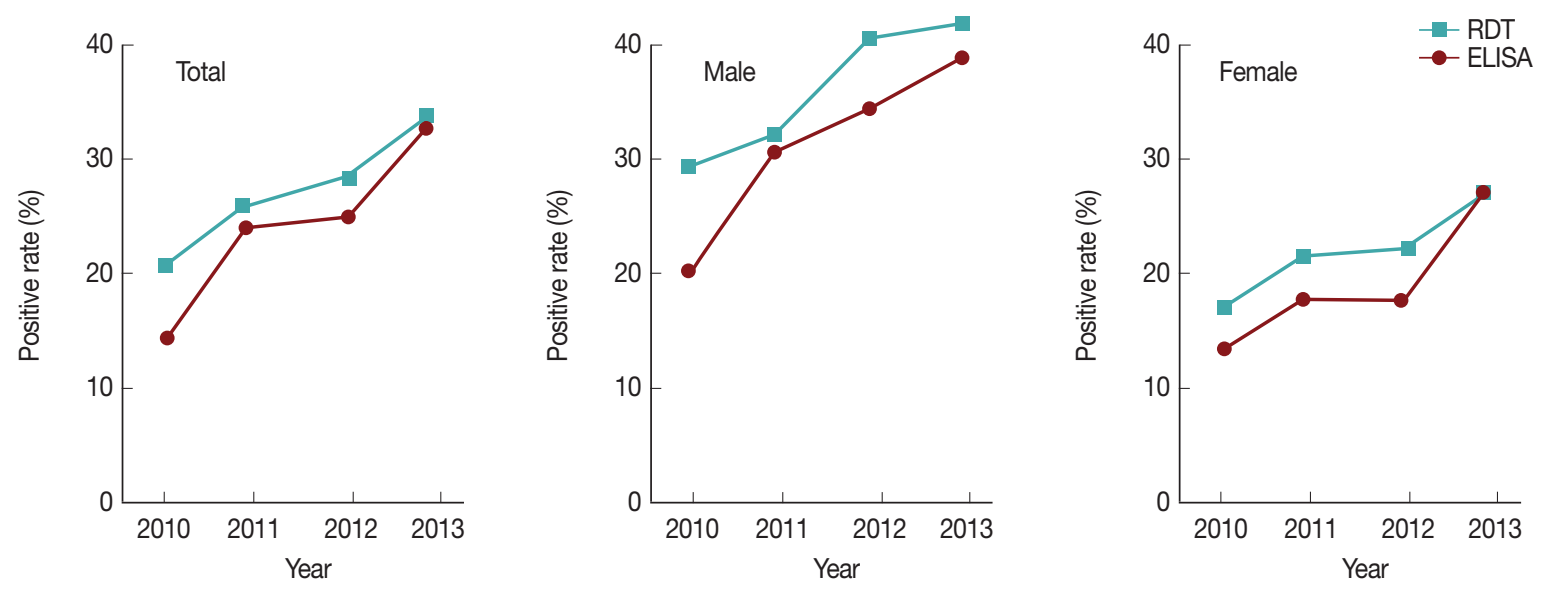

Fig. 2. Trends in positive seroprevalence rate according to gender in the surveyed area. 


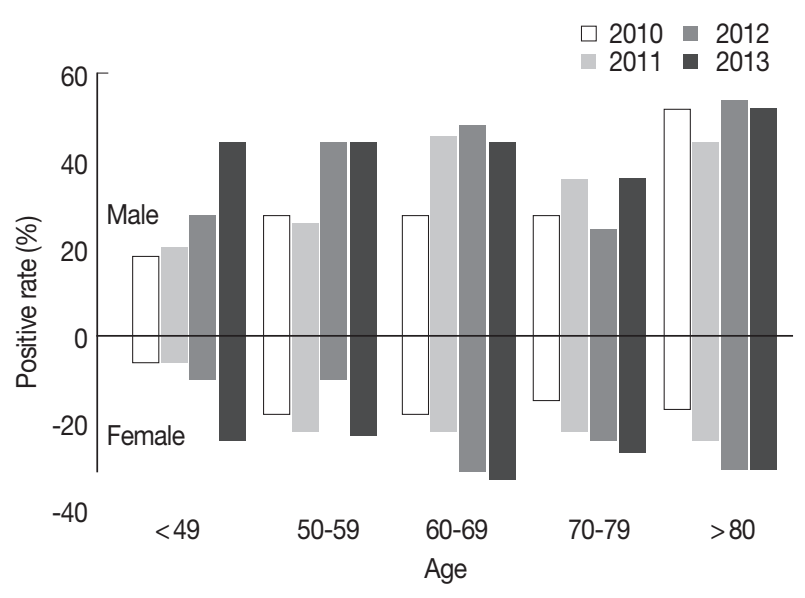

Fig. 3. Comparison of the positive rates of anti-Toxoplasma antibody by gender and age. The positive rates at all age groups in women showed a gradual increase from 2010 to 2013. The same overall increase was observed in men, but surges were observed between 2011-2012 in the age 50's group, and between 20102011 in the age 60's group. The seroprevalence at the 70's group was lower than that of the other age groups regardless of gender.
In contrast, it only increased from $21.7 \%$ (200/921) in to $25.5 \%$ (253/993) in 2011 by RDT. Although a surge was not observed as in the ELISA test, the RDT positive seroprevalence also showed an increasing trend in subsequent years, to $28.9 \%$ (272/940) and 33.1\% (277/838) in 2012 and 2013, respectively (Table 1; Fig. 2).

The positive rate of men was always higher than that of women, and men showed an explosive surge, whereas it was more gradual in women. Nevertheless, the positive seroprevalence showed a steady increasing trend in both genders (Fig. 2).

As expected, both genders showed lower seroprevalence in the below 50 years old age group. The positive rates at all age groups in women showed a gradual increase from 2010 to 2013. The same overall increase was observed in men, but surges were observed during 2011-2012 in the age 50's group, and during 2010-2011 in the age 60's group. The seroprevalence at the 70's group was lower than that of other age groups regardless of gender (Fig. 3).

Table 2. Discrepancy between ELISA and RDT seroprevalence of toxoplasmosis in Gyodong-do (Island), 2010-2013

\begin{tabular}{|c|c|c|c|c|c|}
\hline \multirow{2}{*}{ Year } & \multicolumn{5}{|c|}{$\mathrm{OD}(\%)$} \\
\hline & $0.0-0.14^{a}$ & $0.15-0.24^{a}$ & $0.25-0.34^{b}$ & $0.35-0.44^{b}$ & Over $0.45^{b}$ \\
\hline 2010 & 36/685 (5.3\%) & 48/101 (47.5\%) & $31 / 44(70.5 \%)$ & 24/29 (82.8\%) & $61 / 62(98.4 \%)$ \\
\hline 2011 & $16 / 471$ (3.4\%) & $34 / 283(12.0 \%)$ & $31 / 55$ (56.4\%) & 40/44 (90.0\%) & $132 / 132(100 \%)$ \\
\hline 2012 & $25 / 414$ (6.0\%) & 49/304 (16.1\%) & $42 / 60(70.0 \%)$ & 32/38 (84.2\%) & $124 / 124(100 \%)$ \\
\hline 2013 & $9 / 206$ (4.4\%) & $38 / 363(10.5 \%)$ & $60 / 97$ (61.9\%) & $44 / 46$ (95.7\%) & $126 / 126(100 \%)$ \\
\hline
\end{tabular}

aELISA negative, but RDT positive.

${ }^{\mathrm{b}} \mathrm{RDT}$ positive rate in ELISA positive.
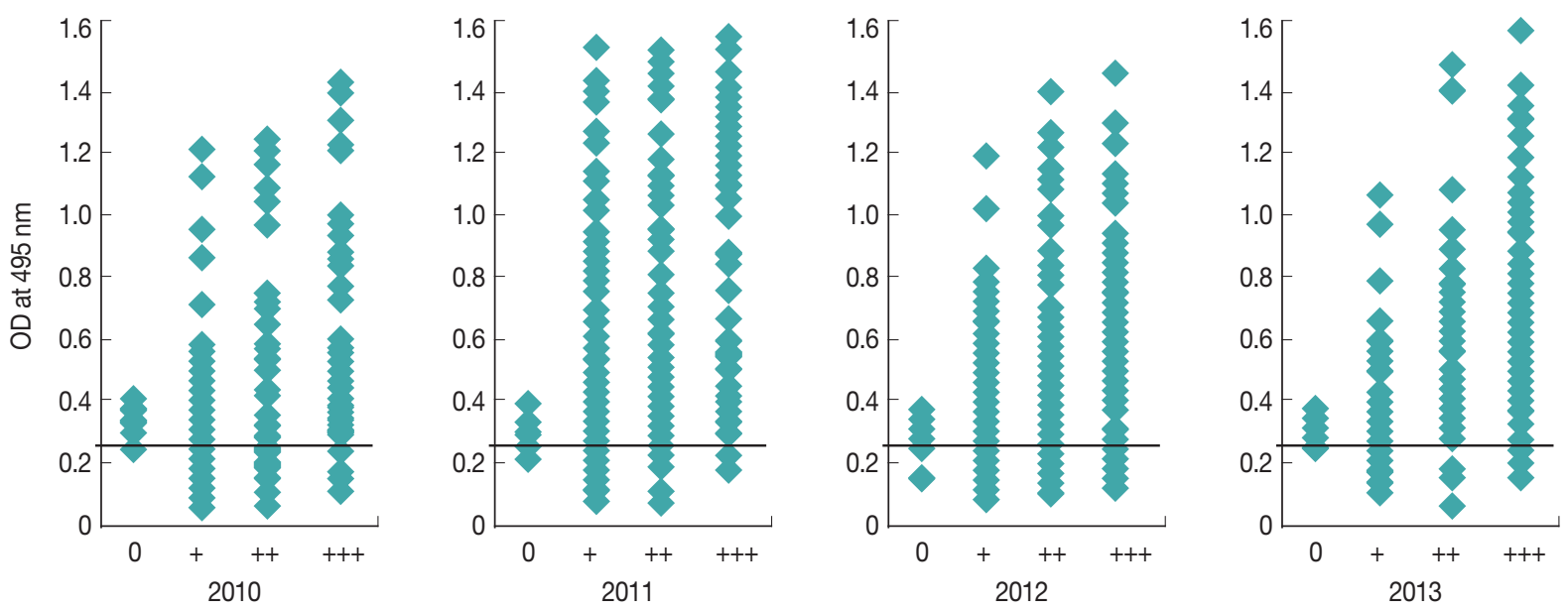

Fig. 4. Comparison of the distribution of positive anti-Toxoplasma antibody titers of the residents in the area. OD line of 0.25 means the positive cut-off of this survey. 


\section{Recent sudden surge of toxoplasmosis}

In 2010, ELISA detected 135 positives among 921 (14.7\%) and RDT detected more sensitively 202 positives (21.9\%). However, RDT detected 87.4\% (118 sera) of ELISA positives except for those sera of controversial OD just above the cut-off value; instead, it detected more positives in ELISA-negatives of $10.7 \%$ (84 sera). This pattern was maintained in 2011, 2012, and 2013 with the increasing seroprevalence of $23.1 \%, 23.6 \%$, and $32.1 \%$ by ELISA and $25.5 \%, 28.9 \%$, and $33.1 \%$ by RDT, respectively (Table 1).

\section{Discrepancy between ELISA and RDT}

A cut-off value of 0.25 optical density (OD) at $495 \mathrm{~nm}$ was considered positive with the laboratory ELISA kit we used [14]. ELISA values agreed fairly well with RDT results under 0.15 OD and above $0.35 \mathrm{OD}$, but discrepancies appeared around the $0.15-0.35$ range. At the OD 0.15-0.24 range, RDT could detect $16.1 \%(169 / 1,051)$ more positive cases. At the OD 0.25 0.34 range, RDT agreed with ELISA in 64.1\% (164/256) of cases (Table 2). Thus, ELISA at this range showed a false positive rate of $35.9 \%$ (92/256), which is a rather high value to be comfortable to accept.

Comparison of the distribution of positive anti-Toxoplasma antibody titers of the residents in the area showed that a fair number of ELISA negative cases below the OD 0.25 cut-off value were positive by RDT (Fig. 4).

\section{DISCUSSION}

Since Soh et al. [20] first reported the seropositive rate of $5.6 \%$ in 373 Koreans by skin test using toxoplasmin in 1960, several serological methods, such as ELISA, ILA, and indirect fluorescent antibody test (IFAT) have been developed for detection of T. gondii infection (Fig. 5). However, most of these methods need whole cell lysates of T. gondii as an antigen which is expensive and time-consuming to prepare. To overcome these disadvantages, we have developed a detection method in the form of rapid diagnostic test (RDT) using recombinant proteins as antigens [19].

The seroprevalence of $T$. gondii has remained fairly stable since 1960 until recently. A major surging increase was observed from 2010 among residents living in Gyodong-do, Incheon, Korea. The RDT results confirmed this trend. The surging increase in the seroprevalence may have been caused by several factors that can reflect environmental and socioeco- nomic changes in Korea. As Korea is becoming economically ever more affluent, health consciousness is increasing, along with environmental awareness, resulting in the increase in organic agriculture with far less use of pesticides throughout the country [21,22].

The improvement in the environment has caused an increase in the local fauna, thus the potential for Toxoplasma hosts has also increased. Our previous studies have been performed around the border of Korea, one of the most naturally preserved areas in the world [23]. Not surprisingly, a relatively high population of local fauna would result in a high seroprevalence of intermediate hosts for Toxoplasma [24]. Sometimes they are captured by a snare to be consumed among families and relatives. Furthermore, some Koreans, mostly men, still have the misbelief that the raw viscera of animals, both domestic and wild, have special nutrients for their stamina, so they eat them raw. This may in some part explain the higher Toxoplasma seroprevalence in men observed in our study, besides being more socioeconomically active.

In recent years, Korea has seen an alarming increase in the elderly population, and also single-households. This again has caused an explosive increase in pets, and besides the common ones like dogs and cats, exotic animals are also being adopted. These exotic animals are not always obtained legally, and some may harbor diseases $[25,26]$. Interaction among pets and these feral counterparts are also common in the countryside. Especially troublesome is the increase in feral cats. These cats are

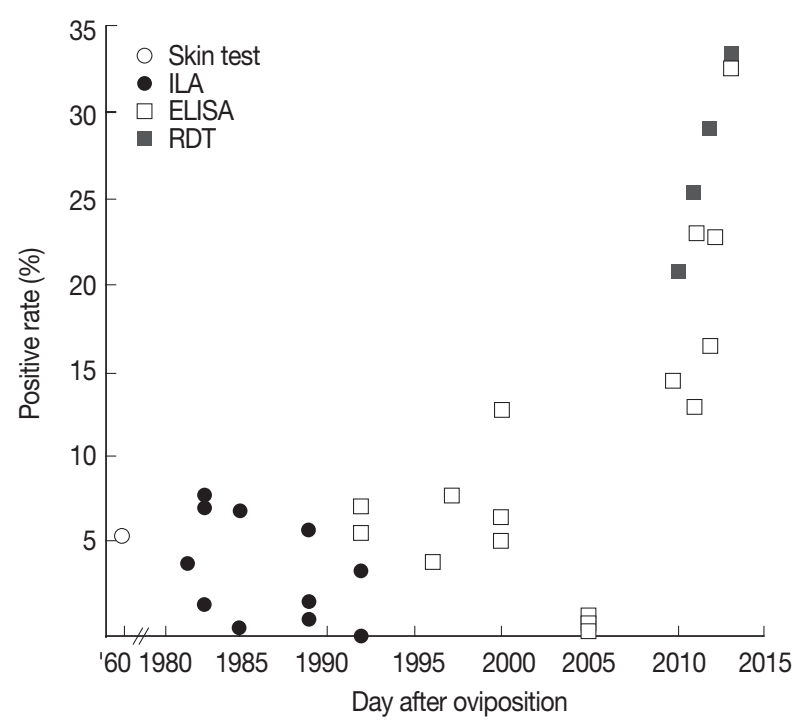

Fig. 5. Trends of positive rates of the surveys of $T$. gondii antibodies in Korea. 
ubiquitous in Korea, and they have occupied the top of the food chain in wildlife of Korea with increasing oocyst-shedding rate.

Meat consumption in Korea has increased dramatically recently. Both domestic and imported meat consumption has increased. Combined with the organic fervor, domestic freerange animals are in high demand, which could be another potential route for Toxoplasma infection [21,27]. Domestic meat supply is insufficient, so a large amount must be imported. Some of them may have been imported from high endemic nations. Indeed, pork has been imported without any inspection of T. gondii [28].

Gangwha-gun is known as the outbreak site of toxoplasmic lymphadenitis by the ingestion of tissue-cysts from pork which was fed in a backyard pigsty. Regardless of pig farm or house pigsty, pigs have been bred under conditions where cats can access easily. They are served as popular foods in domestic festivals, wedding receptions and funeral receptions, and local markets. This may presumably explain the surging of positive rates on the area, if pork had been served undercooked. These factors, combined with its isolated location may have provided a high worm burden to the inhabitants of the island.

Korea is on the verge of becoming an advanced country with an almost 100\% full health-coverage; however, the seroprevalence of toxoplasmosis in certain areas is surging recently. Another factor contributing to the surge may be climatic changes, as the Korean peninsula is experiencing sub-tropical weathers during the warm periods of the year. As a result, communicable disease patterns are also changing, with tropical diseases becoming more common $[29,30]$.

A peculiarity of the RDT needs to be addressed in regard to our study. A cut-off value of 0.25 optical density (OD) at 495 $\mathrm{nm}$ was considered positive with the laboratory ELISA kit we used. Our previous study has determined the overall specificity and sensitivity of the RDT to be $100 \%$ and $97.1 \%$, respectively [19]. ELISA values agreed fairly well with RDT results under 0.15 OD and above 0.35 OD, but discrepancies appeared around the 0.15-0.35 range (Table 2).

Comparison of the distribution of positive anti-Toxoplasma antibody titers of the residents in the area showed that a fair number of ELISA negative cases below the OD 0.25 cut-off value are positive by RDT (Fig. 4). At the OD 0.15-0.24 range, RDT could detect 16.1\% $(169 / 1,051)$ more positive cases. These cases may represent an early or acute toxoplasmosis.

On the other hand, RDT agreed with ELISA in $64.1 \%$
(164/256) of cases at the OD 0.25-0.34 range. This could be interpreted as the ELISA at this range showing a false positive rate of 35.9\% (92/256), or RDT having a low detection rate. Both explanations are problematic. ELISA uses T. gondii whole cell lysate as the antigen, while RDT uses only rSAG1A-GRA2 antigen. Therefore, the discrepancy may be explained in view of the patient's history. A chronic infection history implies abundant antibodies against various antigens, such as SAGs, GRAs, and MICs, which could be detected by ELISA. RDT would be limited in this respect, as only 2 antigens are detected. As previous studies have suggested, the seroprevalence of this area has been high, so chronic cases would not be rare, which would be detected by ELISA alone, and the recent surge in seroprevalence indicates an increasing incidence of new cases, which would be better detected by RDT. Of course, these discrepancies only appear at the 0.25 cut-off value, and in the majority of the cases, ELISA and RDT agreed on the results. A combind method of using both ELISA and RDT at these levels would be appropriate.

Toxoplasmosis is prevalent throughout the world, in both humans and environment, but clinical manifestations are somewhat uncommon, so it is being mainly neglected in major health policies. However, our study reveals a different story, and that a worrying one. A major surge in the seroprevalence, coupled with a change in disease characteristics at any point, may cause a major health threat. As history has revealed, an insignificant retrovirus in the past has caused a near chaotic crisis called AIDS.

It is necessary to find both symptomatic and asymptomatic toxoplasmic patients and confirm the risk factors for further infection in the area. In addition, the problems may not be limited to the island. Indeed, the proposed causes in the study may be applied to a full-scale national survey to screen the national toxoplasmic seroprevalence. In this respect, a national health policy would be required, and with a population of over 50 million in South Korea alone, a rapid and effective screening method will be helpful.

In conclusion, it is necessary to find both symptomatic and asymptomatic toxoplasmic patients and confirm the risk factors for further infection in the area. In addition, the problems may not be limited to the island. So, the postulated causes in this study may be applied to a full-scale national survey to screen the national toxoplasmic seroprevalence. Repeated surveys performed on a fixed time interval with more simple method such as RDT to supplement the ELISA is recommend- 
ed to define the characteristics of the infection as well as to find new infections.

\section{ACKNOWLEDGMENT}

This study was supported by a research grant from the Korea Association of Health Promotion (no. 2015-01), Republic of Korea.

\section{CONFLICT OF INTEREST}

We have no conflict of interest related to this study.

\section{REFERENCES}

1. Black MW, Boothroyd JC. Lytic cycle of Toxoplasma gondii. Microbiol Mol Biol Rev 2000; 64: 607-623.

2. Furtado JM, Smith JR, Belfort R Jr, Gattey D, Winthrop KL. Toxoplasmosis: a global threat. J Glob Infect Dis 2011; 3: 281-284.

3. Tenter AM, Heckeroth AR, Weiss LM. Toxoplasma gondii: from animals to humans. Int J Parasitol 2000; 30: 1217-1258.

4. Montoya JG, Remington JS. Management of Toxoplasma gondii infection during pregnancy. Clin Infect Dis 2008; 47: 554-566.

5. Song KJ, Shin JC, Shin HJ, Nam HW. Seroprevalence of toxoplasmosis in Korean pregnant women. Korean J Parasitol 2005; 43: 69-71.

6. Weiss LM, Dubey JP. Toxoplasmosis: A history of clinical observations. Int J Parasitol 2009; 39: 895-901.

7. Choi WY, Nam HW, Kwak NH, Huh W, Kim YR, Kang MW, Cho SY, Dubey JP. Foodborne outbreaks of human toxoplasmosis. J Infect Dis 1997; 175: 1280-1282.

8. Kim MH, Choi YK, Park YK, Nam HW. A toxoplasmic uveitis case of a 60-year-old male in Korea. Korean J Parasitol 2000; 38 : 29-31.

9. Park YH, Han JH, Nam HW. Clinical features of ocular toxoplasmosis in Korean patients. Korean J Parasitol 2011; 49: 167-171.

10. Tsubota N, Hiraoka K, Sawada Y, Watanabe T, Ohshima S. Studies on latex agglutination test for toxoplasmosis. 2. Evaluation the microtiter test as a serological test for toxoplasmosis in man. Jpn J Parasitol 1977; 26: 286-290.

11. Kobayashi A, Hirai N, Suzuki Y, Nishikawa N, Watanabe N. Evaluaion of a commercial Toxoplasma latex agglutination test. Jpn J Parasitol 1977; 26: 175-180.

12. Choi WY, Nam HW, Youn JH, Kim WS, Kim WK. Toxoplasma antibody titers by indirect latex agglutination test in patients of Kangnam St. Mary's hospital and Cheju medical center. Korean J Parasitol 1989; 27: 171-175.

13. Choi WY, Nam HW, Youn JH, Kim DJ, Kong Y, Kang SY, Cho SY. Detection of antibodies in serum and cerebrospinal fluid to Toxoplasma gondii by indirect latex agglutination test and en- zyme-linked immunosorbent assay. Korean J Parasitol 1992; 30: 83-90.

14. Hong SJ, Chong CK, Lee K, Kim TS, Hong YP, Ahn HJ, Kim HY, Ko AR, Kim YJ, Nam HW. Maintained seroprevalence of toxoplasmosis among the residents of Jeju island, Korea. Korean J Parasitol 2011; 49: 309-311.

15. Yang HJ, Jin KN, Park YK, Hong SC, Bae JM, Lee SH, Choi HS, Hwang HS, Chung YB, Lee NS, Nam HW. Seroprevalence of toxoplasmosis in the residents of Cheju island, Korea. Korean J Parasitol 2000; 38: 91-93.

16. Ahn HJ, Cho PY, Ahn SK, Kim TS, Chong CK, Hong SJ, Cha SH, Nam HW. Seroprevalence of toxoplasmosis in the residents of Cheorwon-gun, Gangwon-do, Korea. Korean J Parasitol 2012; 50: 225-227.

17. Choi WY, Nam HW, Yoo JE. Toxoplasmacidal effect of HL-60 cells differentiated by dimethylsulfoxide. Korean J Parasitol 1988; 26: 229-238.

18. Sohn WM, Nam HW. Western blot analysis of stray cat sera against Toxoplasma gondii and the diagnostic availability of monoclonal antibodies in sandwich-ELISA. Korean J Parasitol 1999; 37: 249-256.

19. Song KJ, Yang Z, Chong CK, Kim JS, Lee KC, Kim TS, Nam HW. A rapid diagnostic test for toxoplasmosis using recombinant antigenic N-terminal half of SAG1 linked with intrinsically unstructured domain of gra2 protein. Korean J Parasitol 2013; 51: 503-510.

20. Soh CT, Lee SJ, Ahn YG. Latent infection by Toxoplasma gondii in Korea. Yonsei Med J 1960; 1: 52-54.

21. Dubey JP, Hill DE, Rozeboom DW, Rajendran C, Choudhary S, Ferreira LR, Kwok OC, Su C. High prevalence and genotypes of Toxoplasma gondii isolated from organic pigs in northern USA. Vet Parasitol 2012; 188: 14-18.

22. Meerburg BG, De Craeye S, Dierick K, Kijlstra A. Neospora caninum and Toxoplasma gondii in brain tissue of feral rodents and insectivores caught on farms in the Netherlands. Vet Parasitol 2012; 184: 317-320.

23. Kim KC. Preserving biodiversity in Korea's demilitarized zone. Science 1997; 278: 242-243.

24. Kim DG, Park JH, Kim JL, Jung BK, Jeon SJ, Lim H, Lee MY, Shin EH, Klein TA, Kim HC, Chong ST, Song JW, Baek LJ, Chai JY. Intestinal nematodes from small mammals captured near the demilitarized zone, Gyeonggi province, Republic of Korea. Korean J Parasitol 2015; 53: 135-139.

25. André MR1, Adania CH, Teixeira RH, Silva KF, Jusi MM, Machado ST, de Bortolli CP, Falcade M, Sousa L, Alegretti SM, Felippe PA, Machado RZ. Antibodies to Toxoplasma gondii and Neospora caninum in captive neotropical and exotic wild canids and felids. J Parasitol 2010; 96: 1007-1009.

26. McIntyre KM, Setzkorn C, Wardeh M, Hepworth PJ, Radford $\mathrm{AD}$, Baylis M. Using open-access taxonomic and spatial information to create a comprehensive database for the study of mammalian and avian livestock and pet infections. Prev Vet Med 2014; 116: 325-335. 
27. Tilahun G, Tiao N, Ferreira LR, Choudhary S, Oliveira S, Verma SK, Kwok OC, Molla B, Saville WJ, Medhin G, Kassa T, Aleme H, Gebreyes WA, Su C, Dubey JP. Prevalence of Toxoplasma gondii from free-range chickens (Gallus domesticus) from Addis Ababa, Ethiopia. J Parasitol 2013; 99: 740-741.

28. Yang Z, Cho PY, Ahn SK, Ahn HJ, Kim TS, Chong CK, Hong SJ, Cha SH, Nam HW. A surge in the seroprevalence of toxoplasmosis among the residents of islands in Gangwha-gun, Incheon, Korea. Korean J Parasitol 2012; 50: 191-197.
29. Kim JY, Goo YK, Zo YG, Ji SY, Trimarsanto H, To S, Clark TG, Price RN, Auburn S. Further evidence of increasing diversity of Plasmodium vivax in the Republic of Korea in recent years. PLoS One 2016; 11: e0151514.

30. Jeong YE, Lee WC, Cho JE, Han MG, Lee WJ. Comparison of the epidemiological aspects of imported dengue cases between Korea and Japan, 2006-2010. Osong Public Health Res Perspect 2016; 7: 71-74. 